\title{
Absorption of Glycine and L-Alanine by the Human Jejunum *
}

\author{
Bertram Fleshler, $\dagger$ James H. Butt, $\ddagger$ and James D. Wismar \\ (From the Department of Medicine, Western Reserve University School.of Medicine at \\ Cleveland Metropolitan General Hospital, Cleveland, Ohio)
}

Most, if not all, ingested protein is degraded into amino acids, which are then absorbed. Absorption of amino acids has been studied in intact animals, everted gut sacs, and in other preparations of intestine. These studies have been reviewed recently $(1,2)$. Comparatively little is known, however, about amino acid absorption in the human. Kuroda and Gimbel (3) showed that when racemic amino acids were placed in the isolated ileal loop of a patient operated on for ulcerative colitis, the L-isomer disappeared faster than the D-isomer. Cummins (4) reported a directly proportional increase in the amount of DLmethionine that disappeared from a length of gut when the concentration of the amino acid was doubled. The kinetics of absorption of L-methionine at various sites in the human small intestine were determined by Schedl and Clifton (5). The uptake of certain amino acids by human intestinal biopsy specimens is dependent, at least in part, on active transport $(6,7)$.

This report presents results of studies on absortion of glycine and L-alanine in human subjects. These amino acids were chosen for study because considerable information is available about their absorption by in vitro preparations. Glycine and L-alanine in man appear to be absorbed by active transport processes and to share a common absorptive pathway for which L-alanine has greater affinity. These findings agree with the results of studies in tissue preparations.

* Submitted for publication March 17, 1966; accepted June 2, 1966.

Supported by U. S. Public Health Service grant ROI-AM-08780.

$\dagger$ Recipient of Career Development Award IK3 AM1506-01.

Address requests for reprints to Dr. Bertram Fleshler, Cleveland Metropolitan General Hospital, 3395 Scranton Road, Cleveland, Ohio 44109.

$\ddagger$ Present address: Wright Patterson Air Force Base, Dayton, Ohio.

\section{Methods}

Studies were performed in three normal adult male subjects. Fifty-five separate studies were carried out: 25 in the first, 21 in the second, and 9 in the third subject. Each individual was intubated with a tube assembly consisting of two polyvinyl tubes joined along their lengths by a solvent, tetrahydrofuran. One tube had an inlet (perfusion opening) that was $15 \mathrm{~cm}$ proximal to the distal recovery opening in the other tube. The sites of the openings were marked with mercury, and the tube position was identified at the beginning and end of each study by image intensifier fluoroscopy. The perfusion opening was positioned just distal to the duodenojejunal junction and repositioned at this site at the start of each study. Tube progression during each study was minimal, and the tip never passed farther than one jejunal loop. The subjects tolerated the tube in place for 3 to 4 days and continued to eat and to maintain normal ward activity. The tube was then removed and the cycle begun again after an interval of at least 3 days.

Each study was done in the morning after an overnight fast during which water intake was permitted. The studies were performed as "steady state" experiments with the jejunal segment constantly perfused with the same solution. Perfusion was done with a peristaltic pump ${ }^{1}$ set to deliver at a constant rate of $12 \mathrm{ml}$ per minute, and the amount of fluid delivered during each period was measured. Recovery of the fluid from the opening $15 \mathrm{~cm}$ distal to the perfusing site was maintained by siphonage. The aspirate was collected in ice and frozen until analysis. Each study began with a 30-minute equilibration period in which the test solution was perfused and the intestinal contents were aspirated. Although the analyses of these initial aspirates yielded results generally similar to those of the later periods, they are not included in this report. Perfusion was continued after the equilibration period with constant aspiration. Experimental aspirates were collected for six successive 15minute periods for Subjects 1 and 2 and for four periods for Subject 3 ; each aspirate was analyzed separately.

The perfusion solution contained $0.5 \mathrm{~g}$ per $100 \mathrm{ml}$ of polyethylene glycol (PEG), ${ }^{2}$ a nonabsorbable reference marker having a molecular weight of 3,000 to 3,700 ;

\footnotetext{
1 Harvard Apparatus Co., Dover, Mass.

2 Matheson, Coleman and Bell, Norwood, Ohio.
} 
either glycine ${ }^{3}$ or L-alanine ${ }^{3}$ or a mixture of the two; and sufficient $\mathrm{NaCl}$ to make the final osmolality approximately $300 \mathrm{mOsm}$ per $\mathrm{kg}$. In one study mannitol was substituted for sodium chloride. Only one perfusate was tested each study day.

Using the instruments and methods indicated, we determined the following for each perfusate and for the aspirates collected during each 15-minute period: volume (milliliters), $\mathrm{pH}$ (units), 4 osmolality by freezing point depression (milliosmoles per kilogram), 5 PEG concentration (milligrams per $100 \mathrm{ml}$ ) (8), sodium concentration (milliequivalents per liter) on a Baird clinical photometer, ${ }^{6} \alpha$-amino nitrogen (milligrams per milliliter) by the copper-complexing method modified by Kekki (9), and amino acid concentration (millimoles per liter) by column chromatography according to modifications of the method of Spackman, Stein, and Moore (10, 11) adapted for an amino acid autoanalyzer system. ${ }^{7}$ No deproteinization procedure was required.

Absorption of amino acid was calculated by adaptation of a formula generally used $(12,13)$ : amino acid absorbed (millimoles) $=$ [volume perfused (liters)] [ $\mathrm{AA}_{1}$ $-\mathrm{AA}_{2}\left(\mathrm{PEG}_{1} / \mathrm{PEG}_{2}\right)$ ], where $\mathrm{AA}_{1}$ and $\mathrm{AA}_{2}$ are the concentrations (millimoles per liter) of amino acid in the perfusate and the aspirate, respectively. $\mathrm{PEG}_{1}$ and $\mathrm{PEG}_{2}$, similarly, are the concentrations (milligrams per $100 \mathrm{ml}$ ) of PEG in the perfusate and aspirate. This calculation assumes that PEG truly is a nonabsorbable reference marker. PEG has been used in similar experiments, and the assumption appears justified, at least for water soluble substances such as the amino acids used in this study (14). The average amount of PEG recovered in the present study was $36 \%$ with a range of 12 to $75 \%$. The presence of endogenous amino acids in the gut lumen could also affect the accuracy of the calculation, but the data to be reported indicate that little con-

TABI,E I

Osmolality and $\mathrm{pH}$ of perfusates and aspirates

\begin{tabular}{cccccc}
\hline \hline \multirow{2}{*}{ Subject } & \multicolumn{2}{c}{ Osmolality } & & \multicolumn{2}{c}{$\mathrm{pH}$} \\
\cline { 2 - 3 } \cline { 5 - 6 } & Perfusates & Aspirates & & Perfusates & Aspirates \\
\hline \multicolumn{4}{c}{$m O s m / k g$} & & \multicolumn{2}{c}{$U$} \\
2 & $306 \pm 7 *$ & $297 \pm 8$ & & $5.5-6.3 \dagger$ & $5.7-7.5$ \\
3 & $296 \pm 9$ & $285 \pm 4$ & & $6.0-6.3$ & $4.9-7.5$ \\
& $310 \pm 14$ & $296 \pm 3$ & & $5.9-6.3$ & $6.2-7.3$ \\
\hline
\end{tabular}

$*$ Mean \pm standard deviation.

$\dagger$ Range.

${ }^{3}$ Nutritional Biochemicals Corp., Cleveland, Ohio. The amino acids were chromatographically pure both by the company's analysis and those performed in this laboratory.

${ }^{4} \mathrm{pH}$ meter 22, Radiometer Company, Copenhagen, Denmark.

5 Advanced osmometer, Advanced Instruments, Inc., Newton Highlands, Mass.

6 Baird Atomic, Inc., Cambridge, Mass.

7 Technicon Instruments Corp., Chauncey, N. Y. taminating amino acid was present during the perfusions. In addition, analysis of intestinal juice showed that free glycine and L-alanine were present at levels of 0.05 mmoles per $\mathrm{L}$ or less, concentrations too low to have influenced the results obtained.

For expression of the data in terms of kinetic constants the figure for amino acid absorption was assumed to be equal to the expression $\mathrm{V}$ (velocity) utilized in enzyme kinetics; $\mathrm{V}$ here has the dimensions of millimoles of amino acid absorbed per 15 minutes per $15 \mathrm{~cm}$ of intestine. A similar treatment of absorption data has been utilized by others $(5,15-17)$. The figure used for substrate concentrations ( $\mathrm{s}$ ) was the geometric mean of the recovered amino acid concentration, uncorrected for changes in PEG, and the amino acid concentration in the perfusate. This represents a reasonable approximation to the true average concentration, an integrated expression since the concentrations of amino acid decrease along the test segment. A Lineweaver-Burk plot of the data was made (18) and Michaelis-Menten constants were derived.

\section{Results}

Osmolality and $p H$ (Table I). The osmolalities of aspirates obtained during perfusion with solutions in the range of $300 \mathrm{mOsm}$ per $\mathrm{kg}$ were slightly lower than those of the perfusates. The differences between perfusates and aspirates for Subjects 1 and 2 were significant $(p<0.01)(19)$, whereas the difference for Subject 3 was questionably significant $(0.1>p>0.05)$. The mean PEG ratios (perfusate $P E G$ concentration divided by sample PEG concentration) were greater than 1 for each subject $(1.01,1.09$, and 1.1 , respectively) indicating a net shift of water into the lumen. The change in osmolality thus results from a flux into the gut of a fluid relatively hyposmolar to the perfusates. The perfusing solution deviated significantly from isosmolality in five studies, in four by error and in one due to the use of high concentrations of amino acids. These studies are indicated in the tables and figures where the absorption data are presented but were not included in the table on osmolality. For these five studies the perfusate and mean aspirate osmolalities were: 245-277, 348-309, 407-318, 363-296, and 620 $376 \mathrm{mOsm}$ per kg. Thus, there was a shift in the osmolality of the lumenal contents towards the 290 to $300 \mathrm{mOsm}$ per $\mathrm{kg}$ range. The perfusates were slightly acid. There were no marked changes in $\mathrm{pH}$ of the aspirates compared with the perfusates. Because $\mathrm{pH}$ units cannot be averaged and the mathematical conversion of $\mathrm{pH}$ units to hy- 
drogen ion concentration in mixed fluids of varying composition is inexact, the perfusates and aspirates were not compared statistically. In Subject 2 (Table I) the lowest value for any aspirate, $\mathrm{pH} 4.9$, was recorded for a single 15-minute specimen. The next lowest value was 5.5. It was estimated that there was a trend towards neutrality in the aspirates resulting from a decrease in hydrogen ion concentration of approximately 0.001 $\mathrm{mEq}$ per L.

$\alpha$-Amino nitrogen content (Table II). The $\alpha$-amino nitrogen content of the perfusates calculated from the amounts of amino acids contained was compared with the $\alpha$-amino nitrogen content
TABLE II

Comparison of calculated and determined $\alpha$-amino nitrogen content of perfusates and aspirates

\begin{tabular}{|c|c|c|}
\hline Subj & $\begin{array}{c}\text { Perfusates } \\
\left.\frac{\text { Determined* }}{\text { Calculated } \dagger} \times 100\right)\end{array}$ & $\left(\begin{array}{c}\text { Aspirates } \\
\left.\frac{\text { Determined } *}{\text { Calculated } \neq} \times 100\right)\end{array}\right.$ \\
\hline & $\%$ & $\%$ \\
\hline 1 & 90 & 93 \\
\hline 2 & 88 & 89 \\
\hline 3 & 97 & 105 \\
\hline
\end{tabular}

* Determined directly (9).

$\dagger$ Calculated from the amounts of amino acids contained in the perfusates.

$\ddagger$ Calculated from the chromatographically analyzed amounts of amino acids in the aspirates.

TABLE III

Absorption of either glycine or L-alanine from human jejunal segment*

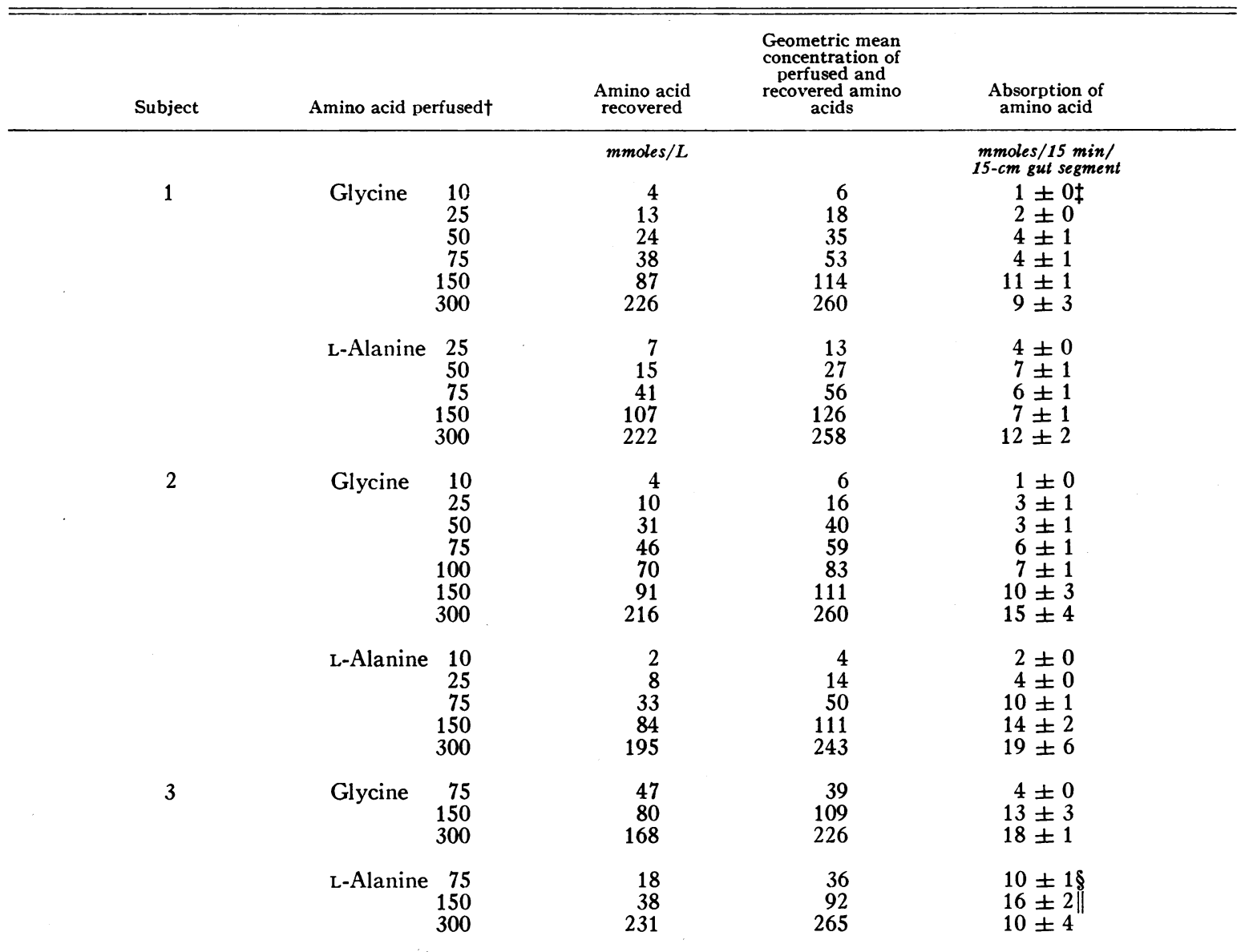

* All figures are rounded to the nearest whole number and represent the mean of either six consecutive periods (Subiects 1 and 2 ) or four periods (Subject 3 ).

† Only a single amino acid concentration was tested on each study day.

$\ddagger$ Mean \pm standard deviation.

$\S$ Perfusate $348 \mathrm{mOsm}$ per $\mathrm{kg}$.

|| Perfusate $407 \mathrm{mOsm}$ per $\mathrm{kg}$. 


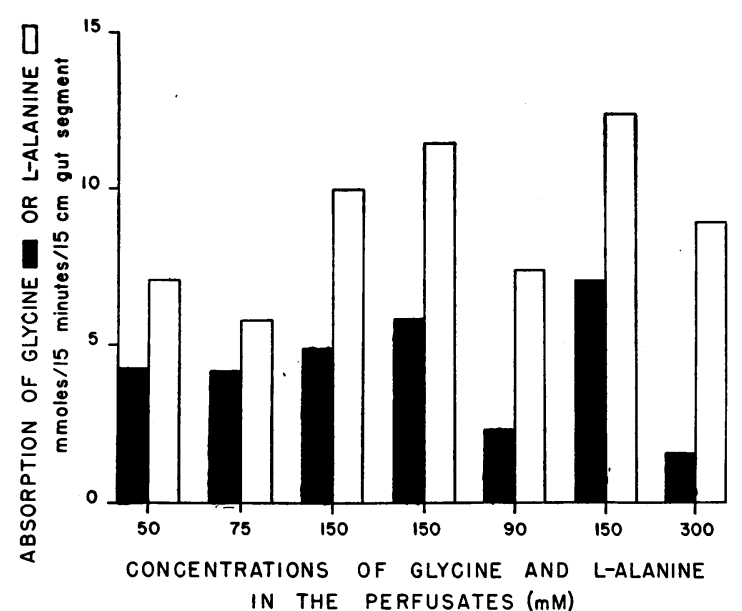

Fig. 1. Absorption of glycine and l-alanine when PERFUSED TOGETHER AT EQUimOLAR CONCENTRATIONS. The first three studies (starting at the left) were performed in Subject 1, the fourth in Subject 2, and the last three in Subject 3. In the first study, perfusate osmolality was $245 \mathrm{mOsm}$ per $\mathrm{kg}$ and in the last two studies, 396 and $620 \mathrm{mOsm}$ per $\mathrm{kg}$, respectively. The height of the column indicates mean absorption.

determined for these solutions. A similar comparison was made between the $\alpha$-amino nitrogen content calculated from the amount of amino acids in the aspirates found by chromatography and the analyzed $\alpha$-amino nitrogen content of the aspirates. The ratios of the determined to calculated $\alpha$-amino nitrogen content of the perfusates were similar to the ratios found for the aspirates. Thus, the $\alpha$-amino nitrogen content of the aspirates could be accounted for by the recovered amino acids indicating little, if any, contamination of the gut segment by endogenous amino acids.

Glycine and L-alanine absorption. In all studies the only amino acids identified in the aspirates were those perfused. Although small amounts of other amino acids undoubtedly were present, the concentrations were too low to appear as peaks at the dilutions at which the chromatograms were run. The results of perfusing either glycine or L-alanine at varying concentrations are shown in Table III. The figure for the amount of amino acid absorbed is the average of the results of six consecutive 15-minute periods for two subjects and for four periods in the third. The amount absorbed during each period, as indicated by the deviation about the mean, was relatively constant, indicating that a reasonable steady state was achieved. The amount absorbed increased generally with increasing perfusion concentration, but over a concentration range of 10 to 300 mmoles per $\mathrm{L}$ the relationships were not directly proportional and tended to approach a limiting value.

When glycine and L-alanine were perfused simultaneously at equimolar concentrations (range 50 to 300 mmoles per L), L-alanine always was absorbed in greater quantities (Figure 1). To

TABLE IV

Absorplion of glycine from human jejunal segment when perfused with L-alanine (150 mmoles per L)*

\begin{tabular}{|c|c|c|c|c|c|c|}
\hline Subject & $\begin{array}{c}\text { Glycine } \\
\text { perfused } †\end{array}$ & $\begin{array}{l}\text { Glycine } \\
\text { recovered }\end{array}$ & $\begin{array}{l}\text { Geometric mean } \\
\text { concentration } \\
\text { of perfused } \\
\text { and recovered } \\
\text { glycine }\end{array}$ & Glycine absorbed & $\begin{array}{c}\text { Geometric mean } \\
\text { concentration of } \\
\text { perfused } \neq \\
\text { and recovered } \\
\text { L-alanine }\end{array}$ & L-Alanine absorbed\& \\
\hline & & mmoles per $L$ & & $\begin{array}{l}\text { mmoles } / 15 \\
\text { min } / 15-c m \\
\text { gut segment }\end{array}$ & mmoles $/ L$ & $\begin{array}{l}\operatorname{mmole} / 15 \\
\text { min/15-cm } \\
\text { gut segment }\end{array}$ \\
\hline 1 & $\begin{array}{r}25 \\
50 \\
75 \\
100 \\
150\end{array}$ & $\begin{array}{r}22 \\
45 \\
63 \\
80 \\
117\end{array}$ & $\begin{array}{r}23 \\
47 \\
68 \\
89 \\
132\end{array}$ & $\begin{array}{l}1 \pm 0 \| \\
2 \pm 1 \\
2 \pm 1 \\
4 \pm 2 \\
5 \pm 2\end{array}$ & $\begin{array}{l}117 \pm 7 \| \\
120 \pm 7 \\
120 \pm 8 \\
121 \pm 8 \\
115 \pm 8\end{array}$ & $\begin{array}{l}16 \pm 1 \| \\
12 \pm 2 \\
10 \pm 4 \\
11 \pm 3 \\
10 \pm 3\end{array}$ \\
\hline 2 & $\begin{array}{r}25 \\
50 \\
90 \\
100 \\
150\end{array}$ & $\begin{array}{r}20 \\
39 \\
71 \\
78 \\
114\end{array}$ & $\begin{array}{r}22 \\
44 \\
78 \\
88 \\
131\end{array}$ & $\begin{array}{l}1 \pm 0 \\
2 \pm 1 \\
4 \pm 1 \\
2 \pm 3 \\
6 \pm 1\end{array}$ & $\begin{array}{l}112 \pm 7 \\
108 \pm 8 \\
115 \pm 4 \\
115 \pm 10 \\
117 \pm 5\end{array}$ & $\begin{array}{l}15 \pm 2 \\
16 \pm 2 \\
13 \pm 2 \\
11 \pm 5 \\
12 \pm 2\end{array}$ \\
\hline
\end{tabular}

* All figures are rounded to the nearest whole number and represent the mean of six consecutive periods.

† Only a single glycine concentration was tested each day.

$\$ 150$ mmoles per $\mathrm{L}$.

$\$ 150 \mathrm{mmoles}$ per $\mathrm{L}$ perfused.

Mean \pm standard deviation. 
test further the competition between glycine and L-alanine, we perfused the two together at varying concentrations of each. A level of L-alanine was sought that permitted studies to be performed with varying glycine concentrations but with the total osmolality maintained at $300 \mathrm{mOsm}$ per $\mathrm{kg}$. On the basis of these preliminary experiments, an L-alanine concentration of 150 mmoles per L was chosen. The results of simultaneous perfusion of L-alanine ( 150 mmoles per L) with varying glycine concentrations are shown in Table IV. At each perfusate, concentration of glycine the amount absorbed was less than the amount absorbed when glycine was perfused alone (Table III). Over the range of glycine concentrations tested ( 25 to 150 mmoles per L), no inhibition of L-alanine absorption was found when the data for L-alanine perfused with glycine (Table IV) were compared with the data for L-alanine perfused alone at the same concentration, 150 mmoles per $\mathrm{L}$ (Table III). Absorption of L-alanine was less in both subjects, however, at the highest glycine concentration tested (150 mmoles per L) compared with the lowest $(25$ mmoles per L). These differences, in all probability, represent day-to day

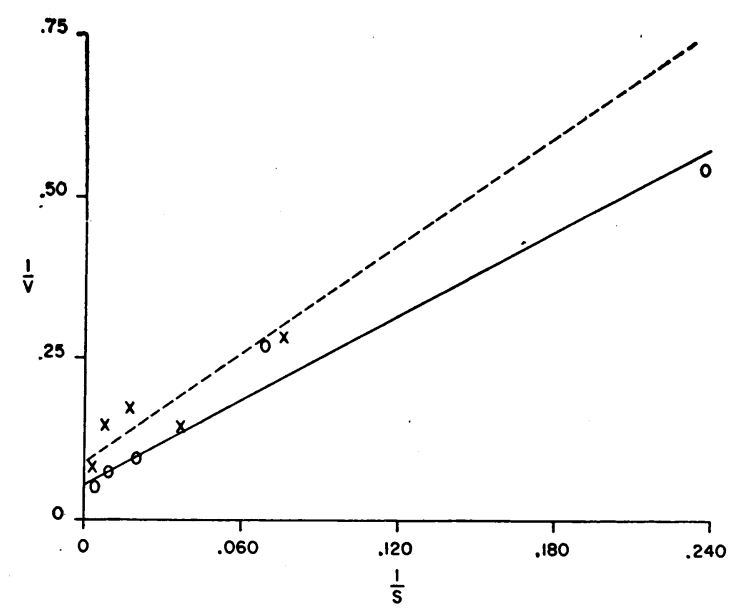

Fig. 2. Lineweaver-BURK Plots OF L-ALANine ABSORPTION IN SUBJECTS 1 (INTERRUPTED LINE) AND 2 (Continuous LINE). The abscissa $(1 / \mathrm{s})$ is the reciprocal of the geometric mean concentration (millimoles per liter) of L-alanine perfused and L-alanine recovered. The ordinate $(1 / \mathrm{V})$ is the reciprocal of the mean amount of L-alanine absorbed (millimoles per 15 minutes per $15-\mathrm{cm}$ gut segment). The lines were drawn by the method of least squares. $\mathrm{X}$ indicates the data points for Subject 1,0 for Subject 2. Kinetic constants derived from this graph are shown in Table V.
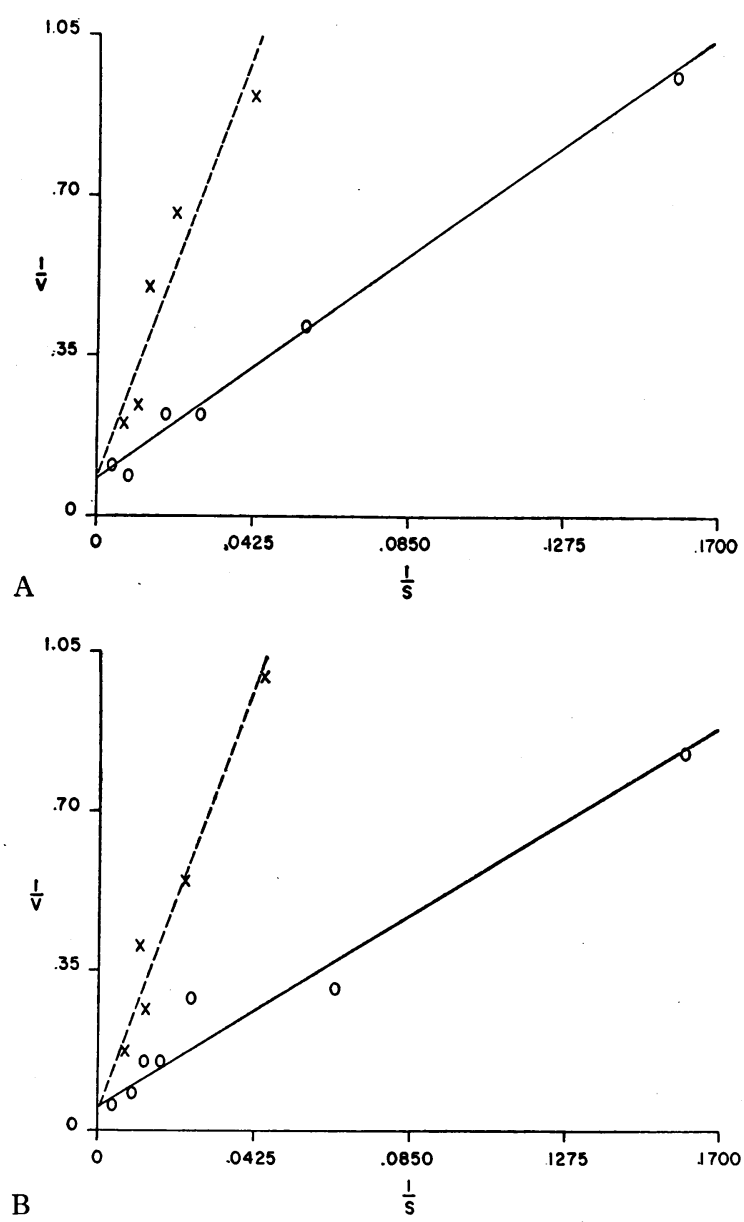

Fig. 3. LineweAVER-BURK PLOTS OF GLYCINE ABSORPTION (CONTINUOUS LINES) IN SUBJECtS 1 (A) AND 2 (B). Kinetic constants derived from these plots are shown in Table V. Lineweaver-Burk plots for glycine absorption when varying concentrations of glycine were perfused with L-alanine (150 mmoles per L) are shown as interrupted lines. The lines were drawn by the method of least squares, and the data points are indicated. The slope of the lines for glycine absorption in the presence of L-alanine is increased compared with the slope for glycine alone, but the intercept on the ordinate is approximately the same. This configuration is consistent with competitive inhibition.

variations, since the geometric mean concentrations did not vary appreciably either during the double amino acid studies or as compared with L-alanine perfused alone.

Kinetic constants. In Figure 2 the reciprocals of the values shown in the last two columns of Table III for L-alanine for Subjects 1 and 2 are plotted according to the method of Lineweaver and Burk (18); lines derived from the data were de- 
termined by the method of least squares. The intercept of any line with the ordinate yields a value equal to $1 / \mathrm{V}_{\max }$ where the expression $\mathrm{V}_{\max }$ refers to the maximal velocity of the reaction or, in this case, to the maximal rate of absorption in a 15minute period for the $15-\mathrm{cm}$ segment of gut tested. The apparent Michaelis constant $(\mathrm{Km})$, which is numerically equal to the substrate concentration producing half the maximal absorption rate, was calculated from the formula $\mathrm{Km}=\left(\mathrm{V}_{\max }\right)$ (slope). The values for $V_{\max }$ and $\mathrm{Km}$ are shown in Table V.

Figure 3 shows Lineweaver-Burk plots for glycine absorption (continuous lines) for Subjects 1 and 2 derived from the values in the last two columns of Table III. Kinetic constants are shown in Table V. Figure 3 also shows plots for the competition studies (interrupted lines) derived from the last two columns under glycine in Table IV. The plot of glycine absorption when glycine was perfused with L-alanine (150 mmoles per L) intercepted the ordinate at approximately the same point as did the line for glycine alone. This relationship is consistent with that expected when competitive inhibition is observed.

Kinetic constants were not calculated for Subject 3 , since relatively few studies were done on this subject and the perfusion concentrations used were too close to $\mathrm{V}_{\max }$ to permit such calculations. The data from this subject, however, generally conform to the absorption data found in the other two subjects.

Sodium content. Because the osmolality of the perfusing solutions was kept relatively constant, the amount of $\mathrm{NaCl}$ used in the perfusates was determined by the concentration of amino acid. Sodium concentration (milliequivalents per liter)

TABLE V

Apparent kinetic constants for intestinal absorption of glycine and $\mathrm{L}$-alanine*

\begin{tabular}{|c|c|c|c|c|}
\hline \multirow[b]{2}{*}{ Subject } & \multicolumn{2}{|c|}{ Glycine } & \multicolumn{2}{|c|}{ L-Alanine } \\
\hline & $\mathrm{Km}$ & $V_{\max }$ & $\mathrm{Km}$ & $V_{\max }$ \\
\hline & mmoles & $\begin{array}{l}\text { mmoles } \\
\text { absorbed// } \\
15 \mathrm{~min} / \\
15-\mathrm{cm} \text { gut } \\
\text { segment }\end{array}$ & mmoles/ & $\begin{array}{c}\text { mmoles } \\
\text { absorbed// } \\
15 \text { min/ } \\
15-\mathrm{cm} \text { gut } \\
\text { segment }\end{array}$ \\
\hline 1 & 75 & 13 & 34 & 12 \\
\hline 2 & 77 & 16 & 38 & 18 \\
\hline
\end{tabular}

*Abbreviations: $\mathrm{Km}=$ Michaelis constant, $\mathrm{V}_{\max }=$ maximal velocity,
TABLE VI

Comparison between predicted ana determined sodium values of perfusates and aspirates

\begin{tabular}{ccc}
\hline \hline Subject & Perfusates & Aspirates \\
\hline & & \\
1 & $-1 \pm 2^{*}$ & $m E q / L$ \\
2 & $-1 \pm 2$ & $+4 \pm 2^{*}$ \\
3 & $+9 \pm 4$ & $+9 \pm 6$ \\
\end{tabular}

$*$ Mean difference \pm standard error.

thus could be calculated as [osmolality (milliosmoles per kilogram) - amino acid concentration (millimoles per liter) ]/2. The same formula with the recovered amino acid concentration substituted was applied to the aspirates and compared with the measured sodium concentration. The actual and predicted sodium concentration values agreed closely (Table VI). The differences between the predicted and determined values for both perfusates and aspirates for each subject were not significant ( $p>0.05$ for each comparison). Thus sodium, presumably as $\mathrm{NaCl}$, apparently replaced amino acid absorbed from the intestinal contents on a mole-for-mole basis. When mannitol, a nonabsorbable sugar, was substituted for $\mathrm{NaCl}$ in one study (Subject 2), glycine absorption was not decreased. The absorption of glycine perfused at 75 mmoles per $\mathrm{L}$ with mannitol was $5 \pm 2$ mmoles per 15 minutes per $15-\mathrm{cm}$ gut segment and with $\mathrm{NaCl}$ was $6 \pm 1$ mmoles per 15 minutes per $15-\mathrm{cm}$ gut segment.

\section{Discussion}

"Absorption" as used in this report refers to the disappearance of the amino acid from the jejunal segment tested. The absorptive process involves a series of sequential steps including entry into the cell; transport or metabolism within the cell, or both; and exit into either blood or lymph. The kinetic data presented are consistent with the idea that at least part of the process may be dependent upon active transport. Active transport processes may be demonstrated by inhibition of transport by interference with the energy balance of the cell and by accumulation of substrate against a concentration gradient (20). In the present study, information regarding the latter way of demonstrating active transport was gathered. The intracellular concentration of either gly- 
cin or L-alanine was not known. Thus, strictly, accumulation against a concentration gradient could not be demonstrated. However, absorption of either amino acid rose as the concentration in the perfusate was increased but tended to approach a limiting value as the ratelimiting mechanism became saturated. This is the observed relationship when active transport processes are involved. Competitive inhibition, although consistent with an active transport process, does not necessarily imply such a process, since in facilitated diffusion such inhibition may also occur. In this study L-alanine $(150$ mmoles per L) inhibited the absorption of glycine. The inhibition was competitive in type since with increasing concentration glycine absorption not only increased but approximated the theoretical maximal absorptive rates $\left(\mathrm{V}_{\max }\right)$ found when glycine alone was perfused. If the observed inhibition were noncompetitive in nature, seen when substances such as phlorizin are used, absorption might increase with increasing substrate concentrations but would not approach maximal absorptive rates. Glycine and L-alanine thus appear to be absorbed, at least in part, by the same ratelimiting mechanism. These findings in humans agree with those in other species $(16,17,21)$.

Kinetic constants, as calculated in this report and by others, are useful methods of comparing the absorption of various amino acids. The constants derived from our data for human subjects certainly are not definitive, but they are of the same order of magnitude as those for hamster everted gut sacs $(16,17)$ and for the isolated rat intestine (21) where the models are less physiologic but better control is possible. Furthermore, the constants determined for L-alanine were lower than those for glycine in all studies. The values for $\mathrm{Km}$ for glycine in our two subjects were 75 and 77 mmoles per L, respectively. For the hamster gut sac, Matthews and Laster (16) found a $\mathrm{Km}$ of 43 mmoles per L, and Finch and Hird (21) calculated a value of 34 mmoles per $\mathrm{L}$ for the rat gut segment. For L-alanine $\mathrm{Km}$ was 34 and 48 mmoles per $\mathrm{L}$ in our subjects, whereas a $\mathrm{Km}$ of 7.5 mmoles per $\mathrm{L}$ was found in the hamster gut sac and 5 mmoles per $\mathrm{L}$ in the rat.

The hypothesis has been advanced that the lipid rich cell membrane shows increased affinity for aminno acịds with more lipophilic sịde chains (21,
22). Thus, L-alanine, with a longer side chain than glycine, would have greater affinity for the absorptive mechanism. Increased affinity usually is associated with lower $\mathrm{Km}$. The competitive effect of L-alanine on glycine absorption and the lower $\mathrm{Km}$ observed for L-alanine than for glycine in our studies are consistent with such postulates.

The validity of the conclusions discussed above depends, in part, on the degree to which the experimental situation corresponded to a true steady state. Changes in osmolality of the aspirates compared with the perfusate, although statistically significant, were small, and $\mathrm{pH}$ was relatively stable. Although endogenous amino acids may be found in the gut lumen when protein or amino acid mixtures are fed (23), under the conditions of this study no amino acids were found other than those perfused, and the total $\alpha$-amino nitrogen content was accounted for by the known amino acids. Thus, it appears reasonable to utilize these data as indicated above.

In the human, unlike results of in vitro experiments, sodium need not be supplied in the perfusate for amino acid absorption to occur. The role of sodium in absorption of amino acids has been considered crucial, though not necessarily specific. Csáky reported significant diminution in active transport by the isolated frog small intestine when lithium or potassium was substituted for sodium as the major cation in the bathing solution (24). The transport of the amino acids L-tyrosine and DL-phenylalanine, the sugar 3,methylglucose, and the pyrimidine uracil were all greatly inhibited under these circumstances. Similar results were reported for the transport of L-tyrosine by the rat everted small intestine (25) and for the transport of glycine, methionine, and a model amino acid by both rat and rabbit jejunal sacs (26). In contrast, amino acid absorption in our subjects was not affected by large variations in the sodium content of the perfusing fluid. Even when no sodium was present, as in experiments when amino acid concentration was 300 mmoles per L, absorption occurred. Furthermore, when mannitol was substituted for $\mathrm{NaCl}$ with $75 \mathrm{mM}$ glycine, absorption was similar to that found when $\mathrm{NaCl}$ was used in the perfusing fluid. Sodium, presumably as $\mathrm{NaCl}$. was consistently supplied to the gut contents as a mole-for-mole replacement of absorhed amino acid. 
The movement of $\mathrm{NaCl}$ into the lumen may be secondary to the absorption of amino acid and has the effect of maintaining the isosmolarity of the jejunal fluid despite changes in the concentration of solutes involved. These data do not indicate that sodium is unnecessary for amino acid absorption in the human. The concentration required probably is quite low, and endogenous sodium may be present in sufficient amounts.

Information as to the variation when a single amino acid concentration is perfused in the same subject on separate days was not obtained. The geometric mean concentration of perfused and recovered L-alanine, 150 mmoles per $\mathrm{L}$, was remarkably stable whether L-alanine was perfused alone or with glycine, although the absorption of L-alanine at this concentration when perfused with differing concentrations of glycine varied from one test day to another. Several factors may be involved in such variation, but the finding that the absorption data in this study were so similar for the subjects tested and could be plotted along a straight line by the Lineweaver-Burk method indicates that the amount of variation was reasonably low.

A variety of problems are involved in studying the kinetics of absorption in man. Simply placing a tube into the gut for lengthy periods and performing repetitive studies in the same subject necessitates considerable patience on the part of both subject and investigator. It is difficult to be certain that exactly the same segment is being tested from day to day since the relation of gut segment to tube may change in an unpredictable fashion. Furthermore, the extent to which the dynamic processes taking place during absorption vary from time to time and subject to subject is unknown. Despite these difficulties, the studies presented demonstate that approximations of steady state conditions can be obtained and that sufficient intra- and inter-subject reproducibility exists to permit tentative conclusions to be drawn concerning the absorption of glycine and L-alanine in the human jejunum.

\section{Summary}

Glycine and L-alanine absorption from the human jejunum was investigated by a "steady state" perfusion technique. Perfusates for jejunal in- tubation contained either glycine or L-alanine, or both, the nonabsorbed indicator, polyethylene glycol, and sufficient sodium chloride so that osmolality approximated $300 \mathrm{mOsm}$ per $\mathrm{kg}$. Aspirates were obtained continuously by siphonage from a site $15 \mathrm{~cm}$ distal to the perfusing site. Osmolality of the aspirates fell only slightly, and $\mathrm{pH}$ rose minimally as compared with the perfusion solutions. $\alpha$-Amino nitrogen content of the aspirates was accounted for by the amounts of perfused amino acids recovered, indicating that the test segment contained no significant quantity of endogenous amino acid. Amino acid absorption was not impaired either by the deletion of sodium from the perfusates or the substitition of mannitol for sodium chloride. A sodium compound, presumably sodium chloride, entered the gut lumen as a replacement for absorbed amino acid on a mole-for-mole basis, maintaining the isosmolalitv of the lumenal contents.

Absorption of either glycine or L-alanine increased as its concentration in the perfusate was raised, but the increase was not directly proportional over the range tested and approached a limiting value. Kinetic constants were calculated by the Lineweaver-Burk method. In two subjects, apparent Michaelis constants were 75 and 77 mmoles per $\mathrm{L}$ for glycine and 34 and 38 mmoles per L for L-alanine. Corresponding apparent maximal velocities (in millimoles per 15 minutes per $15-\mathrm{cm}$ gut segment) were 13 and 16 for glycine and 12 and 18 for L-alanine. At equimolar concentrations ranging from 50 to 300 mmoles per $\mathrm{L}, \mathrm{L}$-alanine absorption always exceeded that of glycine when the two were perfused together. When varying concentrations of glycine were perfused at a constant L-alanine concentration of 150 mmoles per L, glycine absorption decreased in a manner suggestive of competitive inhibition.

These findings in humans are consistent with published data derived from in vitro studies which indicate that glycine and L-alanine are absorbed by active transport processes and that they share a rate-limiting step for which L-alanine has greater affinity.

\section{Acknowledgments}

We are grateful to Dr. Leslie T. Webster, Jr., for his advice. Miss Lillian Tybuszewski's skillful technical assistance was invaluable. 


\section{References}

1. Wilson, T. H. Intestinal Absorption. Philadelphia, W. B. Saunders, 1962.

2. Matthews, D. M., and L. Laster. Absorption of protein digestion products: a review. Gut 1965, 6, 411.

3. Kuroda, Y., and N. S. Gimbel. Selective disappearance of stereoisomers of amino acids from the human small intestine. J. appl. Physiol. 1954-55, 7, 148.

4. Cummins, A. J. Absorption of glucose and methionine from the human intestine; the influence of the glucose concentration in the blood and in the intestinal lumen. J. clin. Invest. 1952, 31, 928.

5. Sched1, H. P., and J. A. Clifton. Kinetics of L-methionine absorption from the human small intestine (abstract). J. Lab. clin. Med. 1963, 62, 1011.

6. Spencer, R. P., T. M. Bow, M. A. Markulis, and K. R. Brody. Enzymatic assay and glucose and amino-acid uptake of intestinal biopsy specimens. Amer. J. dig. Dis. 1963, 8, 419.

7. Thier, S. O., S. Segal, M. Fox, A. Blair, and L. E. Rosenberg. Cystinuria: defective intestinal transport of dibasic amino acids and cystine. J. clin. Invest. 1965, 44, 442.

8. Hydén, S. A turbidimetric method for the determination of higher polyethylene glycols in biological materials. Annals of the Royal Agricultural College of Sweden 1955, 22, 139.

9. Kekki, M. Microdetermination of amino nitrogen as copper complexes. A modification for plasma and urine. Scad. J. clin. Lab. Invest. 1959, 11, 311.

10. Spackman, D. H., W. H. Stein, and S. Moore. Automatic recording apparatus for use in the chromatography of amino acids. Analyt. Chem. 1958, 30, 1190.

11. Piez, K. A., and L. Morris. A modified procedure for the automatic analysis of amino acids. Analyt. Biochem. 1960, 1, 187.

12. Schedl, H. P., and J. A. Clifton. Solute and water absorption by the human small intestine. Nature (Lond.) 1963, 199, 1264.

13. Gray, G. M., and F. J. Ingelfinger. Intestinal absorption of sucrose in man: the site of hydrolysis and absorption. J. clin. Invest. 1965, 44, 390.
14. Jacobson, E. D., D. C. Bondy, S. A. Broitman, and J. S. Fordtran. Validity of polyethylene glycol in estimating intestinal water volume. Gastroenterology 1963, 44, 761.

15. Nathans, D., D. F. Tapley, and J. E. Ross. Intestinal transport of amino acids studied in vitro with L- $\left[{ }^{13} \mathrm{I}\right]$ monoiodotyrosine. Biochim. biophys. Acta (Amst.) 1960, 41, 271.

16. Mathews, D. M., and L. Laster. Kinetics of intestinal active transport of five neutral amino acids. Amer. J. Physiol. 1965, 208, 593.

17. Matthews, D. M., and L. Laster. Competition for intestinal transport among five neutral amino acids. Amer. J. Physiol. 1965, 208, 601.

18. Lineweaver, H., and D. Burk. The determination of enzyme dissociation constants. J. Amer. chem. Soc. 1934, 56, 658.

19. Mainland, D. Elementary Medical Statistics. Philadelphia, W. B. Saunders, 1952.

20. Robinson, J. W. L., J. C1. Jéquier, and F. Taminelli. The measurement of amino-acid absorption in vitro: experimental studies and clinical perspectives. Gastroenterologia (Basel) 1964, 102, 292.

21. Finch, L. R., and F. J. Hird. The uptake of amino acids by isolated segments of rat intestine. II. A survey of affinity for uptake from rates of uptake and competition for uptake. Biochim. biophys. Acta (Amst.) 1960, 43, 278.

22. Lin, E. C. C., H. Hagihira, and T. H. Wilson. Specificity of the transport system for neutral amino acids in the hamster intestine. Amer. J. Physiol. 1962, 202, 919.

23. Nasset, E. S. The role of the digestive tract in protein metabolism. Amer. J. dig. Dis. 1964, 9, 175.

24. Csáky, T. Z. Significance of sodium ions in active intestinal transport of nonelectrolytes. Amer. J. Physiol. 1961, 201, 999.

25. Harrison, H. E., and H. C. Harrison. Sodium, potassium, and intestinal transport of glucose, $l$-tyrosine, phosphate, and calcium. Amer. J. Physiol. 1963, 205, 107.

26. Rosenberg, I., A. Coleman, and L. Rosenberg. Dependence of intestinal amino acid transport on active sodium transport (abstract). Fed. Proc. 1964. 23, 339. 